high seas can be expected to comply with the steering and sailing rules at an appropriate time. Given that ability, and just a touch of good fortune, he will avoid both a collision and an appearance in a court where case law would become much more relevant.

Jinsong Zhao is to be congratulated on undertaking such a detailed study and analysis of an important subject, and in providing such a substantial basis for further discussion.

\title{
REFERENCES
}

Cockcroft \& Lameijer (1976) A Guide to the Collision Avoidance Rules. Stanford Maritime, London. Jinsong Zhao (2008) When do Collision Regulations Begin to Apply? The Journal of Navigation, 61, 515.

\section{The Use of AIS for Collision Avoidance}

\author{
Ivica Tijardovic \\ (Chairman Croation Branch RIN) \\ (Email: ivica.tijardovic@st.htnet.hr)
}

1. INTRODUCTION. As a captain with many plaudits including three nominations for Shipmaster of the Year I understand that people are different, they come from different countries, with different cultures, with different ways of thinking. This is very important to remember at sea in time of collision or close collision situations. It is correct and important to act according to the International Regulations for Preventing Collisions at Sea, but the most important thing is to prevent collision. So officers should not just think "I will keep my present course, because she is the one who has to change her course", but communicate (by AIS message and/or by calling on VHF Channel 16) with her in time and make themselves sure of her intentions. This paper offers some suggestions on how to use AIS in such situations. It should be remembered that AIS is not $100 \%$ reliable and is not a substitute for VHF or radar.

2. ANALYSIS. Suppose that an identified vessel is 12 nautical miles ahead of you and the Closest Point of Approach (CPA) is zero or too small for safe navigation. Write/send her an AIS message, such as: Starboard to Starboard! or Green to Green! or Port to Port! or Red to Red! (If your AIS does not already have these messages stored in the Predefined Safety Related Messages (SRM) List, then save the messages, so you can quickly use them any time they are needed). If she doesn't answer to your AIS message or does not call you or keeps her present (collision) course, call her by name on Channel 16 (VHF), when she is more than 8 nautical miles away from you. You gave her enough time - from 12 to 8 nautical miles - to do something.

3. SUGGESTIONS FOR USE OF AIS. What AIS message should you send to an identified conflicting vessel in a particular situation? I have outlined a 


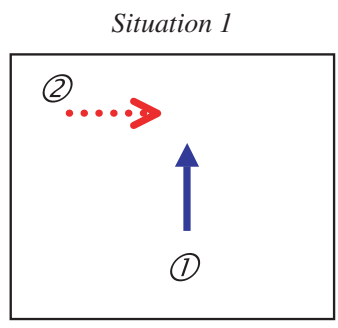

Situation 2

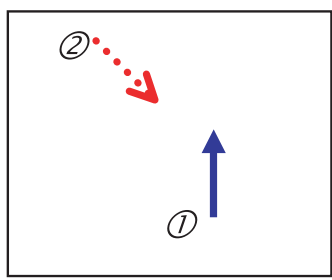

Figure 1. Situations 1-3.

Situation 4

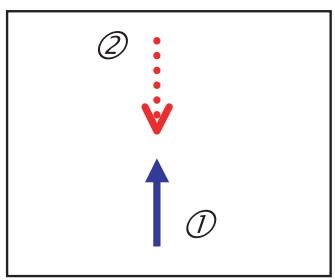

Figure 2. Situation 4.
Situation 3

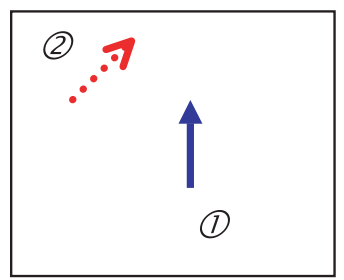


Situation 5

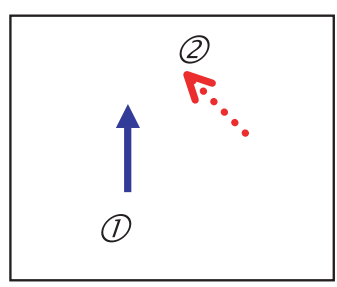

Situation 6

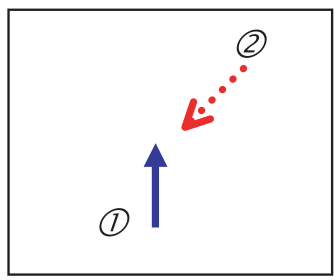

Figure 3. Situations 5-7.
Situation 7

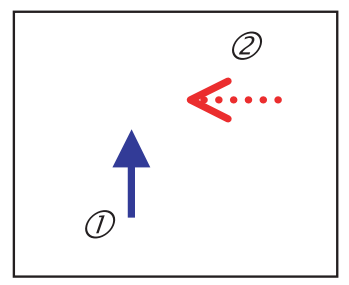

Situation 8

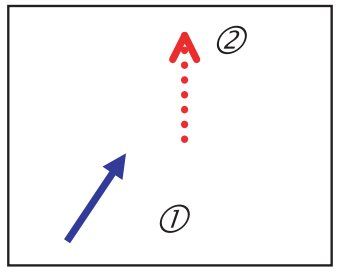

Situation 9

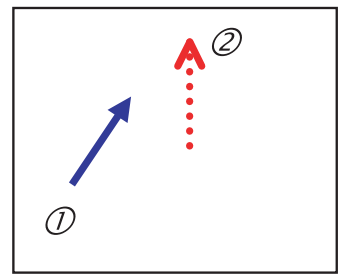

Figure 4. Situations 8 and 9.

Port, you might send the AIS message: Starboard to Starboard! In this case the identified vessel will change her course a few or more degrees to Port and you will also change your course a few or more degrees to Port. You will see then her Starboard side and she will also see your Starboard side.

In Figure 3, illustrating Situations 5, 6 and 7, send to the identified vessel the AIS message: I will change my course to Starboard when you come six nautical miles away from me and then you will see my Red. That means that you will change your course to Starboard to show her your Red light (Port side) and the identified vessel may keep her present course or she may also change her course a few or more degrees to Starboard. If the identified vessel agrees with you, she should acknowledge with: $O K$. If the identified vessel doesn't agree with you, she should call you on Channel 16.

The distance of six nautical miles when you start to change your course is a reasonable, acceptable and safe distance. Of course the distance could be smaller than six nautical miles, but do not leave your course change to the last moment because it may be too late. In congested traffic situations do not wait until the last moment to send the AIS message or make a VHF call.

4. SUGGESTIONS FOR AIS USE WHEN OVERTAKING. In Situations $8,9,10,11$ and 12 you are travelling faster than the identified vessel.

In Situation 8 (Figure 4, Left) send to the identified vessel the AIS message: I will pass astern of you.

In situation 9 (Figure 4, Right) send the AIS message: I will pass two nautical miles ahead of you. If the identified vessel agrees with you, she should send you the following message: $O K$. If the identified vessel does not agree with you, she should call you on Channel 16. The distance of two nautical miles is a reasonable, acceptable and 
Situation 10

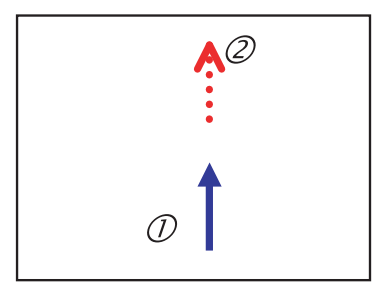

Situation 11

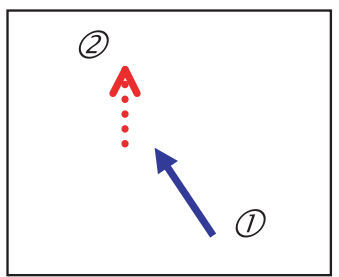

Figure 5. Situations 10 and 11.

Situation 12

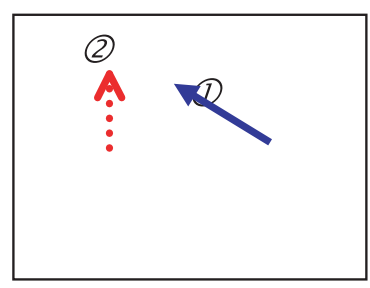

Figure 6. Situation 12.

safe distance. (But the larger the distance, the better). Of course the distance could be less than two nautical miles, but try to keep your vessel out of the way of the identified vessel. Do not come too close to her.

In Situation 10 (Figure 5, Left) send the AIS message to the identified vessel $I$ will overtake Starboard of you or I will overtake Port of you. If the identified vessel agrees with you, she should send you: $O K$. If the identified vessel doesn't agree with you, she should call you on Channel 16.

In Situation 11 (Figure 5, Right) send to the identified vessel AIS message: I will pass astern of you.

In Situation 12 (you see her Green light) (Figure 6) send to the identified vessel the AIS message: I will pass ahead of you. The identified vessel may change her course a few or more degrees to Port to give you more space to pass safely ahead of her, or she may reduce speed to give you enough space to pass safely ahead of her. If the identified vessel changes her course to Starboard to show you her Red, she must let you know about her action and such action must be taken quickly (rudder hard to Starboard), and when the distance between the vessels is between six and three nautical miles, depending on the turning circle characteristics of the identified vessel. To increase the safe distance you may change your course a few or more degrees to Starboard, if necessary. If the distance between you and the identified vessel is less than three nautical miles, and you cannot change your present course to Starboard for some reason (you have another vessel on your Starboard side or shallow water, etc.), then the identified vessel must reduce her speed or change her course to Port significantly and even make a full circle $\left(360^{\circ}\right)$.

If you were a significantly smaller vessel than the identified vessel, it would be reasonable that both vessels change the course a few or more degrees: you to Starboard and the identified vessel to Port. This suggestion is probably the best one for Situation 12, irrespective of the size of the vessels. Situation 12 may be very 
dangerous and it would be better to call the identified vessel on Channel 16 before any action is taken.

5. GENERAL SITUATIONS. In all situations, if the identified vessel does not answer your AIS message or call you on Channel 16, then you call her and tell her your intentions.

In heavy traffic, let CPA be at least one nautical mile, if possible. In situations, particularly somewhere on the ocean, where there are just you and other vessel, there is no need to come too close (CPA less than one nautical mile) to the other vessel. If you have any doubt about her intentions, call her on Channel 16 when you are more than eight nautical miles apart, switch to another channel and ask her: How long are you going to keep the present course and what is your next course? With such information you will know exactly what you have to do for safe navigation.

The position of the AIS display should be close to the Radar (older radars have no AIS display) and VHF receiver, so the officer on watch can talk with an identified vessel and at the same time see AIS and the Radar display. Your AIS display may not always follow the change of bearing by each degree of the identified vessel. The reasons could be that the connection of the ship's gyro-compass to the AIS is not synchronized or is not working correctly. AIS is still not perfect and although the International Telecommunication Union has specified the AIS message update intervals and the AIS dynamic information update interval, in practical terms you may not have the latest up-to-date information on the identified vessel.

When the received AIS signal is weak, your AIS display may show only partial information about the located vessel, and may not show her Name, IMO Number, Call sign, Destination, ETA, etc. The AIS signal may be weak due to the position of the AIS antenna, due to a large distance between the ships, due to some problem of the identified vessel AIS or due to some other reason. If the AIS antenna is positioned close to other ship's antennas (VHF radiotelephone, Radar, Inmarsat, etc.), the received signal may be interrupted or weak from time to time. AIS antennae, like Radar antennae (scanner), have blind or shadow sectors. The higher the position of the AIS antenna, the better the signal will be and the longer the range attainable. The best way to see the effect of a weak AIS signal is when the ship is in port and a co-located vessel ahead/astern of you is working with her cranes (or you may work with your cranes). When the crane covers the AIS antenna the signal will be weak and you may see an interrupted signal or just a part of the information from the co-located vessel.

6. CONCLUSION. It is obvious that AIS still needs some improvements but it is already, even in present conditions, a significant improvement in safety of navigation and together with Radar, it will be of great help to ships' officers when they have to act properly to prevent a possible collision.

In this paper we have tried to make some practical suggestions to officers to help simplify their job in collision and close collision situations. But officers should not forget to look through the navigation bridge windows. The view is still beautiful, more beautiful than any electronic display they have on the bridge or in their hands. It has been reported that even the most sophisticated instruments cannot replace a human eye. 